\title{
MOBILIDADE URBANA: ANTEPROJETO DE UMA CICLOVIA PARA O MUNICÍPIO DE CAJAZEIRAS-PB
}

\author{
URBAN MOBILITY: PROJECT OF A CYCLOVIA FOR THE CITY OF \\ CAJAZEIRAS-PB
}

\author{
Jusiê Sampaio Peixoto Neto ${ }^{1}$ \\ Marjorie Maria Abreu Gomes de Farias ${ }^{2}$ \\ Joálisson Dias Cunha ${ }^{3}$ \\ André Ferreira Costa ${ }^{4}$ \\ Emanoella Bella Sarmento Salgueiro Eliziário Matias ${ }^{5}$ \\ Mirela Davi de Melo ${ }^{6}$
}

\begin{abstract}
${ }^{1}$ Graduando em Arquitetura e Urbanismo pela Faculdade Santa Maria - FSM;
${ }^{2}$ Arquiteta e Urbanista, graduada pela Universidade Federal da Paraíba (UFPB) (2013) e mestre pelo Programa de Pós-graduação em Arquitetura e Urbanismo da Universidade Federal da Paraíba (PPGAU-UFPB) (2015). Atualmente é professora do curso de Bacharelado em Arquitetura e Urbanismo da Faculdade Santa Maria - Cajazeiras-PB. Tem experiência ministrando aulas e trabalhando com iniciação científica nos seguintes temas: acessibilidade, mobilidade, avaliação pósocupação, sistema de espaços livres, avaliação pós-ocupação e representação e concepção de projeto.

3 Possui graduação em Arquitetura e Urbanismo pela Universidade Federal da Paraíba-UFPB (2013). É Especialista em Planejamento Urbano e Gestão de Cidades pelo Centro Universitário de João Pessoa-UNIPÊ. Atualmente é Diretor Geral da Oficina Escola de Revitalização do Patrimônio de João Pessoa-OEJP, atuando nos ramos da construção civil e preservação do patrimônio cultural brasileiro, artes visuais, história da arte e produção cultural. Recentemente lecionou na Faculdade Santa Maria nas áreas de urbanismo: Projeto, Infraestrutura, Teoria e Sustentabilidade, onde contribui como Coordenador de extensão universitária no Plano Municipal de Saneamento Básico de Cajazeiras-PB.

${ }^{4}$ Desde 2016 é professor da Faculdade Santa Maria de Cajazeiras, atuando no curso de Arquitetura e Urbanismo e no curso de Engenharia Civil. Possui graduação em Engenharia Civil pela Universidade Federal da Paraíba (2014), graduação em Construção de Edifícios pelo Instituto Federal de Educação, Ciência e Tecnologia da Paraíba (2014) e especialização em Gerenciamento de Projetos pela Fundação Getúlio Vargas (2016). Tem experiência profissional na área de Engenharia Civil, com ênfase em Gerenciamento e Execução de Obras.

5 Pesquisadora mestra (2015) pelo Programa de Pós Graduação em Arquitetura e Urbanismo, PPGAU - UFPB. Arquiteta e Urbanista, formada pela Universidade Federal da Paraíba (2011). Colaboradora do Laboratório de Acessibilidade (LACESSE) - UFPB desde 2012 e integrante do grupo de pesquisa Qualidade, Acessibilidade, Tecnologia e Percepção do Ambiente Construído, certificado UFPB e CNPq. Coordenadora e docente do curso de Arquitetura e Urbanismo da Faculdade Santa Maria (FSM) de Cajazeiras, na Paraíba.

${ }^{6}$ Possui graduação em Arquitetura e Urbanismo pela Universidade Federal da Paraíba (UFPB 2016), especialização em Gestão de Políticas do Patrimônio Cultural pela Faculdade Maurício de Nassau (2018) e mestrado em Desenvolvimento Urbano (MDU) pelo Departamento de Arquitetura e Urbanismo da Universidade Federal de Pernambuco (UFPE - 2019), canalizando seus estudos para o projeto paisagístico e o bem-estar. Exerce o cargo de arquiteto como técnica na Prefeitura Municipal de Marí/ PB desde 2016, atuando na elaboração de projetos arquitetônicos e urbanos. É docente na Faculdade Santa Maria (FSM) desde 2018.
\end{abstract}


RESUMO: Com os problemas de mobilidade crescendo nos grandes centros urbanos, foi apresentado, em 1976, o documento Planejamento Cicloviário - Uma Política para as Bicicletas, com o intuito de incentivar o uso de bicicletas no cotidiano da sociedade, e minimizar esses problemas que a sociedade enfrenta até hoje, em grande parte devido ao descaso dos governantes com o tema. Felizmente, isso começou a mudar no início do século XXI, de forma modesta e pontual, quase sempre em metrópoles. Enquanto em cidades de pequeno e médio porte, os planos de mobilidade urbana muitas vezes não abordam o tema, a exemplo do município de Cajazeiras-PB, cidade do interior paraibano com mais de 60.000 habitantes e um grande potencial para o uso desse sistema de transporte, uma vez que é impulsionada pela expansão universitária e industrial. Com isso. justifica-se a elaboração de um anteprojeto de uma ciclovia durante este processo de crescimento, com o intuito de valorizar a utilização de meios de transporte não motorizados, evitando, assim, os grandes problemas vivenciados pelas metrópoles no tocante à mobilidade urbana. Portanto, este projeto apresentou como objetivo propor a implantação de uma ciclovia em um recorte urbano do município de Cajazeiras-PB. A metodologia foi qualitativa, consistindo em duas etapas: diagnóstico e projeto. Na primeira, foram verificadas a estrutura urbana e a viabilidade para a implantação da ciclovia. $\mathrm{Na}$ elaboração do projeto, foram utilizados como referência os parâmetros do Manual de Planejamento Cicloviário, elaborados pela Geipot (Empresa Brasileira de Planejamento de Transportes) no ano de 2001. A partir disso, foram elaborados o mapa de uso e ocupação prioritário do Solo, proposta de locação da ciclovia nas margens da BR 230, bem como por dentro da malha urbana, interligando as três principais entradas do município. Também foi demonstrada a proposta de implantação por meio de cortes esquemáticos, vistas e plantas esquemáticas.

DESCRITORES: Ciclovia; Mobilidade Urbana; Planejamento Urbano.

ABSTRACT: With the increasing problems of mobility in the great urban centers, the document Planejamento Cicloviário - Uma Política para as Bicicletas was presented in 1976 aiming to encourage the use of bicycles in the daily life of society, in an attempt to minimize those problems that society faces until today, largely due to the disregard of the rulers with the theme. Fortunately, this began to change at the beginning of the $21^{\text {st }}$ century, in a modest and punctual way, often in metropolises. Small and medium-sized urban mobility plans often do not address the issue, such as the municipality of Cajazeiras-PB, a city in the interior of Paraiba with more than 60,000 inhabitants and great potential for the use of this transportation system, as it is driven by university and industrial expansion. This justifies the elaboration of a preliminary design of a bicycle lane during this growth process, with the purpose of valuing the use of non-motorized means of transportation, thus avoiding the great problems experienced by metropolises in urban mobility. Therefore, this project aimed to propose the implantation of a bicycle lane in an urban area of the municipality of Cajazeiras-PB. The methodology was qualitative, consisting of two stages: diagnosis and design. In the first one, the urban structure and the feasibility 
for the implantation of the bicycle lane were verified. In the project design, reference was made to the parameters of the Cycle Planning Manual developed by Geipot (Brazilian Transport Planning Company) in 2001. From that point on, a map of the use and priority occupation of cycle lane on the banks of BR 230, as well as within the urban network linking the three main entrances of the municipality. The proposal of implantation was also demonstrated through schematic cuts, views and schematic plans.

DESCRIPTORS: Bicycle path; Urban mobility; Urban planning. 


\section{INTRODUÇÃO}

O Brasil, nas últimas décadas, vivenciou um crescimento habitacional urbano de escala sem precedentes. Segundo Reis (2014), em 1950 o Brasil apresentava $36 \%$ da população morando em áreas urbanas e esse valor passou em 2010 para surpreendentes $84 \%$.

Em 1976, foi apresentado o documento Planejamento Cicloviário - Uma Política para as Bicicletas, apresentando sugestões para se implementar uma política nacional que incentivasse a sua utilização como opção de transporte (GEIPOT, 2001).

No entanto, somente em 2004, o governo federal lançou o "Programa Brasileiro de Mobilidade por Bicicletas", valorizando seu uso para que este se eleve à modalidade de transporte sustentável, orientando os poderes municipais e estaduais a executarem ações para que os ciclistas encontrem segurança e infraestrutura adequada (SILVA, 2017).

Mesmo sendo um tema que necessita de atenção especial, o poder público não se despertou para resolver com eficácia os problemas relacionados a mobilidade e a acessibilidade, e é visível que esse problema vem aumentando constantemente. Apesar da melhor adequação das vias e da infraestrutura viária nos últimos anos, na maioria dos municípios, essas adequações favorecem apenas os veículos motorizados, esquecendo-se dos pedestres e ciclistas (SILVA, 2017). Um exemplo disso é o plano de mobilidade urbana da cidade de Cajazeiras, no interior do estado da Paraíba, com população estimada pelo Instituto Brasileiro de Geografia e Estatística (IBGE) de 61.776 pessoas (IBGE, 2018), no qual não foi contemplada nenhuma proposta direcionada para o ciclismo.

Nesse sentido, uma das soluções apontadas corresponde à implantação de ciclovias, uma vez que vários autores apontam seus benefícios, tais como: redução da poluição ambiental, baixo custo e facilidade no uso, facilita o acesso a serviços para pessoas que não possuem outro meio de transporte, requer menos espaço e 
menor custo em infraestrutura urbana, redução no tempo de deslocamento e benefícios para a saúde (OLIVEIRA,2012; COELHO JUNIOR et al., 2015; VALE, 2016; FURTADO, 2018). Portanto, é primordial que a sociedade e os gestores públicos compreendam a importância da utilização, implantação e valorização deste meio de transporte.

Diante do apresentado, é primordial disseminar a importância da implantação de ciclovias, principalmente nas cidades de pequeno e médio porte, visando à promoção de uma melhor mobilidade urbana e evitando que os grandes problemas de mobilidade vivenciados pelas grandes cidades se enraízem nessas durante o seu crescimento.

Considerando que as cidades que implantam ciclovias proporcionam maior comodidade e segurança a quem utiliza de bicicletas para o deslocamento, e que as cidades de grande porte vêm adotando essa prática como medida de redução do caos na mobilidade urbana. A cidade de Cajazeiras, que vem se tornando um polo universitário no sertão paraibano e uma grande produtora de material têxtil, conta com uma grande demanda de alunos e trabalhadores, que são os principais usuários de bicicleta no cotidiano urbano, nesse caso, podem ser beneficiados com a implantação deste modal de transporte.

\section{METODOLOGIA}

Esse trabalho apresenta metodologia qualitativa, que foi elaborada em duas etapas: diagnóstico e projeto.

Cajazeiras situa-se no interior do estado da Paraíba, estando a uma distância de 468 quilômetros da capital do estado. No último censo do IBGE, seu Índice de Desenvolvimento Humano (IDH) foi 0,679. Entretanto, apesar de ser um polo educacional com atrativos a diversos usuários, além das áreas residenciais e comerciais, o município não dispõe de um plano de mobilidade urbana que contemple a existência de ciclovias. 
A partir da pesquisa bibliográfica, encontraram-se dois documentos que serviram de referência para a elaboração desse trabalho: o manual de planejamento cicloviário da Empresa Brasileira de Planejamento de Transporte (GEIPOT) e a norma ABNT NBR 9050/2015.

O trabalho iniciou-se com a busca dos mapas de uso e ocupação do solo do município com o intuito de utilizá-lo para traçar uma ligação entre as três tipologias de uso: a residencial, industrial e educacional. Entretanto, encontrou-se apenas um mapa do ano de 2018 no qual constam as demarcações de: instituições de ensino, instituições religiosas, estação de tratamento de esgoto, limites de bairros e de quadras, demarcação do centro histórico e os nome das ruas, bairros e quadras. Por meio de uma análise espacial com o uso do Google Earth e do mapa do município de Cajazeiras-PB, foi elaborado um mapa de uso e ocupação prioritário do solo disponível em apêndices na prancha 07/07.

Como critério para elaboração do mapa de uso e ocupação prioritário do solo, foi considerado o uso prioritário da quadra e demarcados instituições de ensino, espaços religiosos, espaços industriais e estação de tratamento de esgoto. Os itens foram demarcados pelo mapa de expansão do município.

Foram realizadas as medições das ruas escolhidas para o percurso da ciclovia. O percurso escolhido apresentou como intuito interligar as três principais entradas do município abrangendo o maior número possível de zonas de comércio e serviços (ZCS's), zonas industriais (ZI's) e zonas residenciais (ZR's). Posteriormente foram realizadas visitas in loco para medição das ruas escolhidas que englobaram esse trajeto.

Com o auxílio do programa de desenho técnico da Autodesk, o AutoCad 2016, foram criados cortes e plantas esquemáticas baseadas nas dimensões encontradas e as tipologias foram separadas com os nomes das vias em que elas podem ser implantadas.

Em seguida, foi elaborada a maquete em 3D com o uso do programa SketchUp Pro 2017, também da Autodesk, e aplicado materiais para renderização utilizando o aplicativo Vray 3.4.

A elaboração do anteprojeto atendeu as especificações projetuais do manual de planejamento cicloviário da Empresa Brasileira de Planejamento de Transporte 
(GEIPOT), e nela contendo os parâmetros necessarios para a elaboração projetual da ciclovia, abordando: projeto geométrico, pavimentação, drenagem e iluminação, uma vez que o documento mais recente publicado pelo Ministerio das cidades é o Plano de Mobilidade por Bicicleta nas Cidades de 2007, que toma como base construtiva os paramentros Do manual de planejamento cocloviario.

Os parametros utilizados para o dimensionamento das calçadas atendem ao disposto da ABNT NBR 9050, que determina como mínimo: faixa de serviço de $0,70 \mathrm{~cm}$, altura mínima livre na faixa livre de $2,10 \mathrm{~m}$ e $1,20 \mathrm{~m}$ de faixa livre para pedestre.

\section{RESULTADOS E DISCUSSÃO}

Com uma visão geral de Cajazeiras-PB, fica perceptivo o motivo que leva a cidade a impulsionar a parte mais industrial para o lado sul do município, uma vez que nele se encontram os principais acessos, demarcados com um círculo vermelho e enumerados para facilitar a apresentação, enquanto a BR 230 está demarcada com uma linha amarela.

$\mathrm{Na}$ imagem 01, visualiza-se o percurso proposto para a implantação da ciclovia, onde a parte destacada em vermelho representa as ruas em que a ciclovia deverá ser implantada dentro da malha urbana e o destaque em amarelo representa o percurso na margem da BR 230. Na prancha 03/07, planta esquemática de locação em apêndice, visualiza-se uma visão mais ampla do percurso a qual demarca todas as ruas e cruzamentos, bem como o lado da via em que é proposto a implantação da ciclovia.

Um dos critérios para a criação deste projeto era que houvesse uma ligação entre os três tipos de uso prioritário do solo: residencial, educacional e industrial. Com o aprofundamento do estudo, fazendo ligações entre estes três tipos, ficou perceptivo que somente nas margens da BR 230 poderiam encontrar-se áreas industriais, assim, quando foi analisada as possibilidades os percursos ficaram inviáveis para a implantação, devido a aproximação entre as tipologias, podendo 
encontrar ligações em percursos com menos de $1 \mathrm{~km}$ em todas as opções. Portanto, surgiu a necessidade de avaliar um novo critério para a proposta de trajeto. Com isso, foi proposto que abrangesse o maior número possível de ZED, ZI e ZCS, de forma que todas ficassem interligadas.

Com isso, a malha cicloviária proposta atende aos 12 dos 30 bairros do município, entretanto, ressalta-se que apenas uma ZI e duas ZCS's não são contempladas com a proposta (prancha 01/07 em apêndices). E como a área norte do município, que não é atendida pela proposta, é quase em sua totalidade residencial, com ZR's dos três tipos, o trânsito de ciclistas dentro dessas áreas pode ser realizado em forma de trânsito compartilhado, o que é permitido pelo Código de Trânsito Brasileiro (CTB).

Imagem 1 - Proposta de locação da ciclovia.

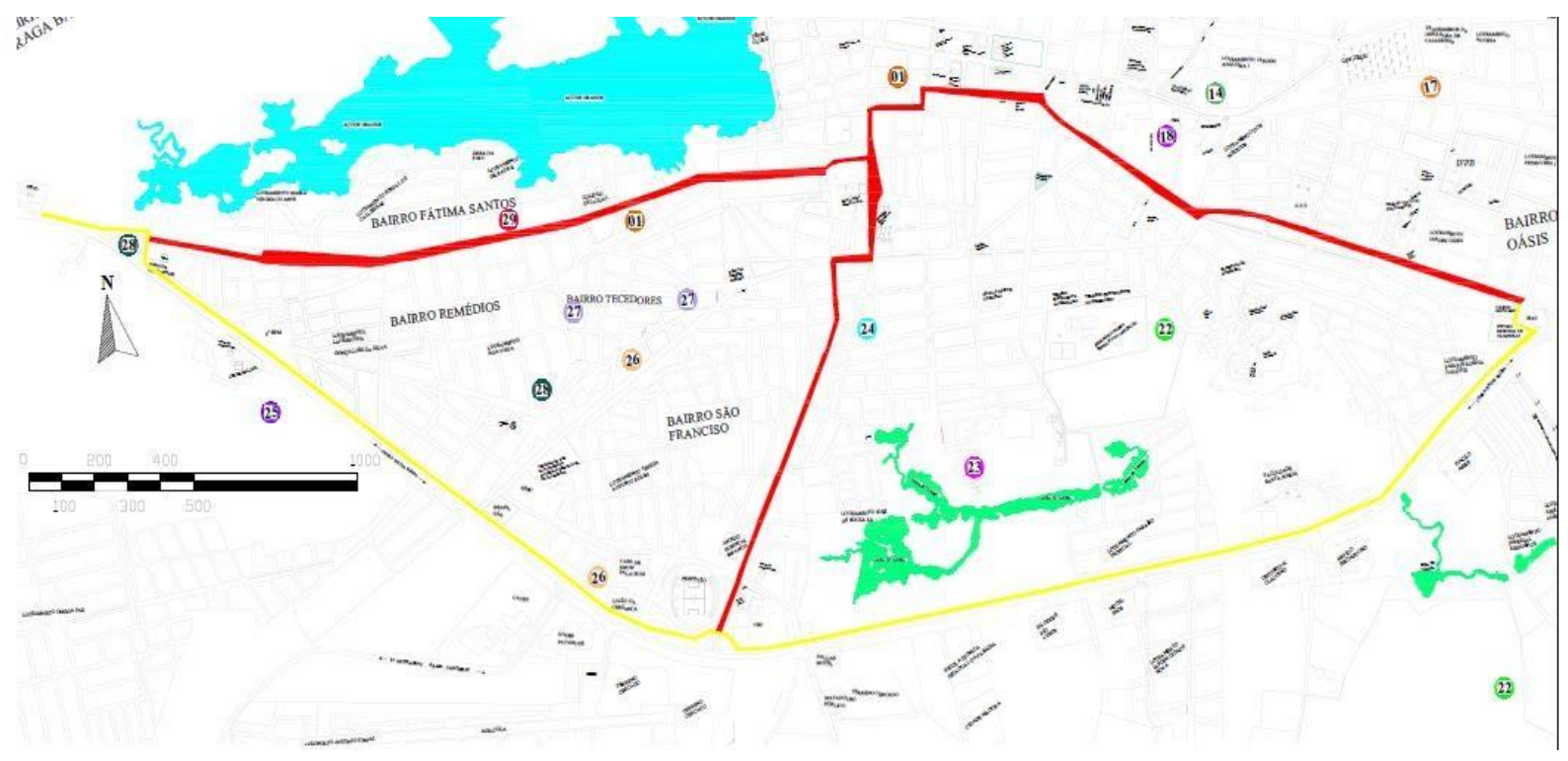

Fonte: Elaborado pelo autor.

Todo o percurso ficou delimitado dentro da malha urbana nas Avenidas: Eng. Coelho Sobrinho; Pedro Moreno Gondim; Júlio Alves do Nascimento e João Rodrigues Alves; e Ruas: Col. Juvêncio Carneiro; Sebastião Bandeira De Melo; Padre Manoel Mariano; Padre José Tomás; Eng. Carlos Pires De Sá; Anísio Rolim; Francisco Aprígio Nogueira e Pedro Américo. 
O esquema de distribuição foi separado pelas três tipologias de uso automotivo encontradas: mão única, que ocorre nas Ruas Pedro Américo, Padre Manoel Mariano e Sebastião Bandeira de Melo; mão dupla; e via duplicada, representadas respectivamente nas imagens 02,03 e 04.

Imagem 2 - Corte esquemático de via de mão única.

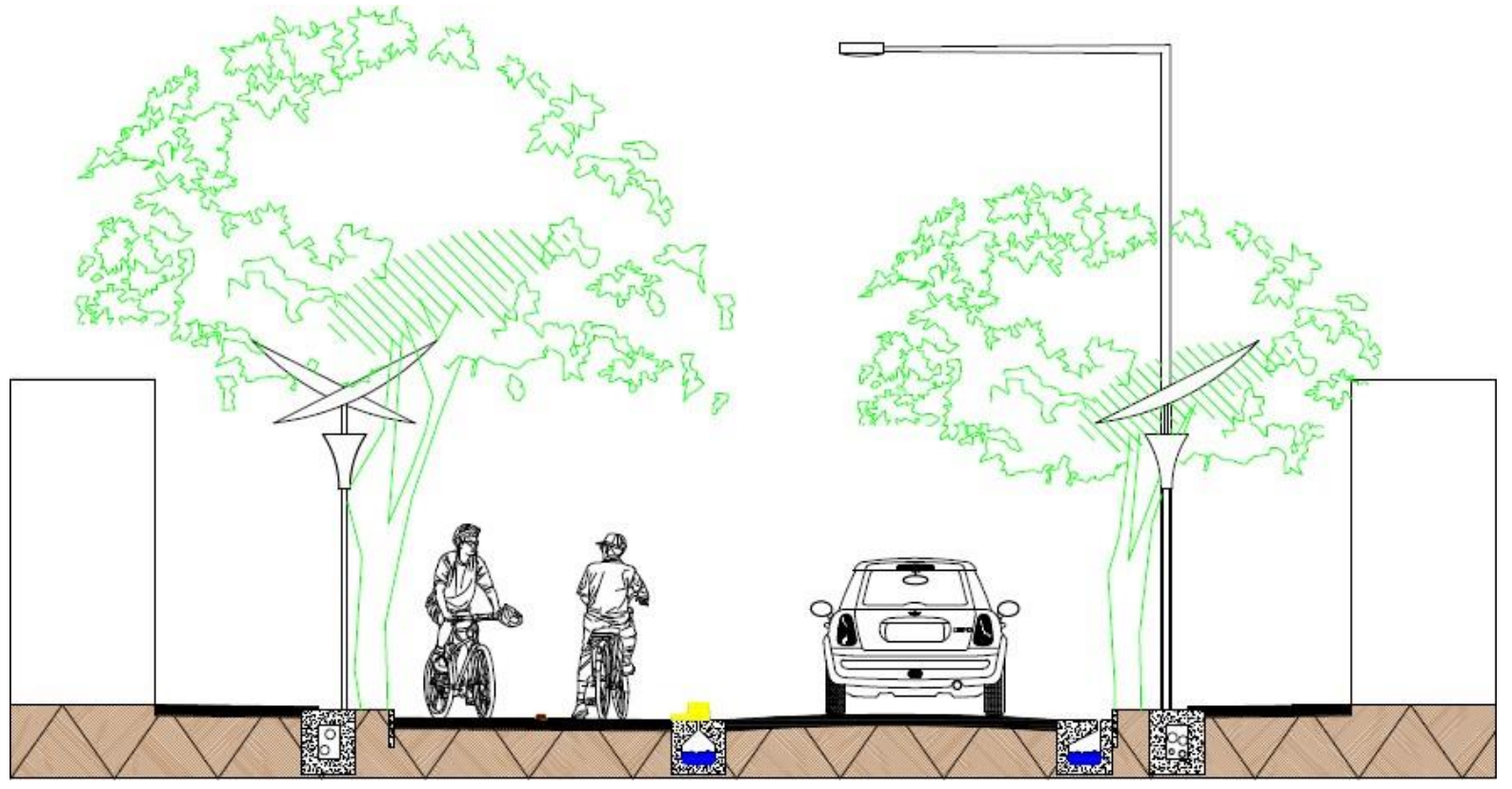

Fonte: Elaborado pelo autor.

A imagem 03 representa as vias de mão dupla, entretanto, nem todas têm essa mesma disposição. Contudo, as dimensões de faixa de serviço e ciclovia e a composição da iluminação e arborização permanecem as mesmas. O que pode modificar é a dimensão das calçadas e a presença ou ausência de estacionamento. Ao lado da ciclovia, estará sempre acompanhada do duto de rede elétrica na faixa de serviço, com exceção de vias duplicadas, como é o caso da imagem 06, com esse duto no canteiro central. 
Imagem 3 - Corte esquemático de via de mão dupla.

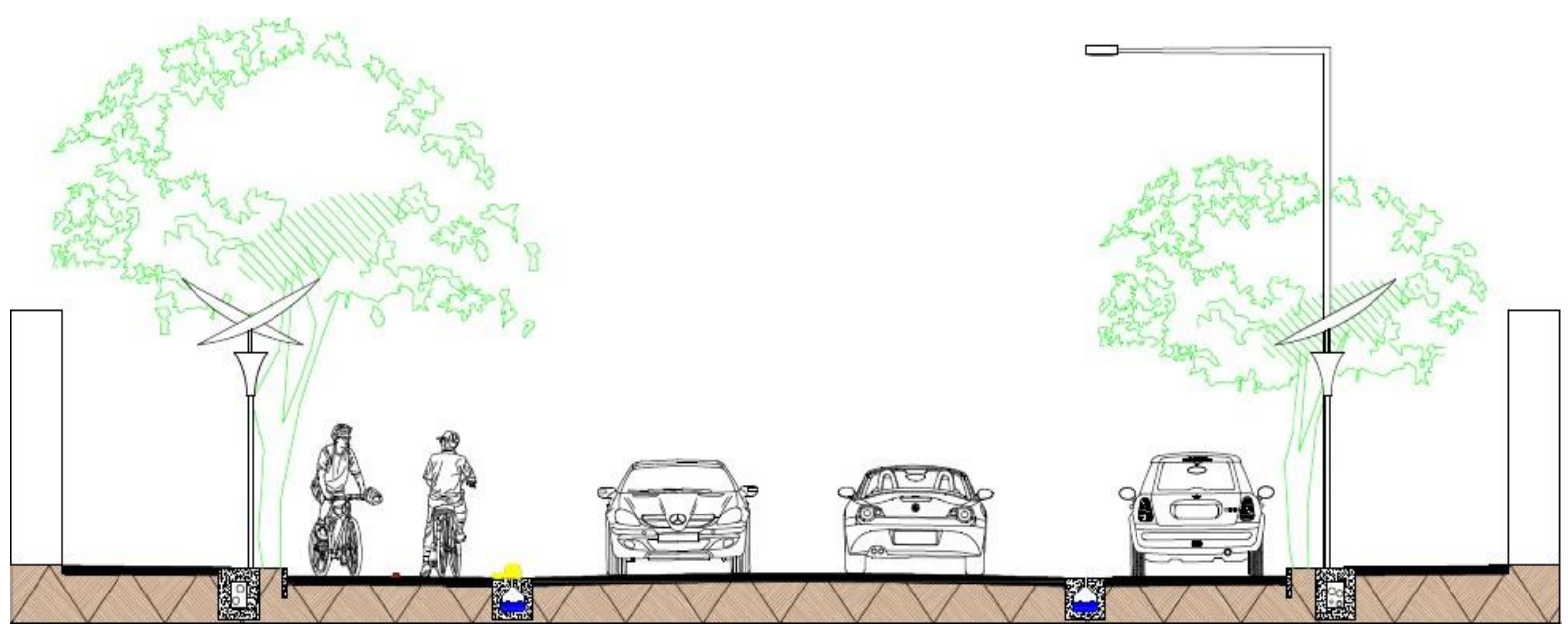

Fonte: Elaborado pelo autor.

O padrão de via duplicada apresenta, assim como nas vias de mão dupla, variações de lado da ciclovia, dimensões de calçadas, presença ou não de estacionamento e neste caso em determinados pontos pode-se haver dimensões diferentes na faixa de rolagem de veículos.

Imagem 4 - Corte esquemático de via duplicada.

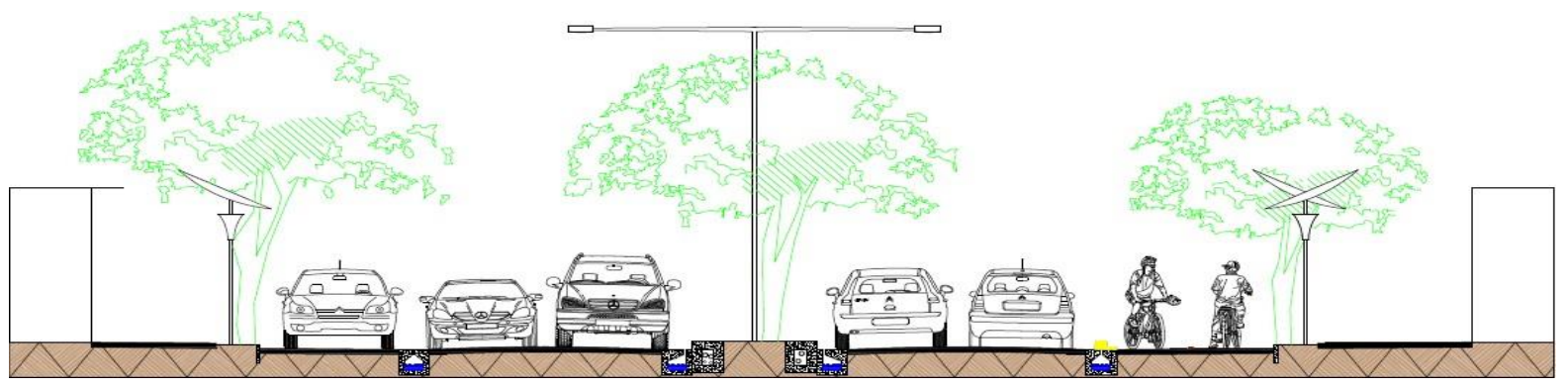

Fonte: Elaborado pelo autor.

A imagem 07 demonstra de forma simplificada o funcionamento e distribuição da ciclovia, independente de qual padrão ela tenha, o esquema é o mesmo, calçada, que pode variar de largura, sentido do fluxo de veículos automotor, faixa de serviço, com iluminação, vegetação e a caixa de rede elétrica, com exceção das vias com 
canteiro central, ciclovia com 2.55 m de largura, tachão de separação de sentido da mesma e a barreira de concreto funcional em cima da caixa de drenagem pluvial.

$\mathrm{Na}$ imagem 5, visualiza-se um corte renderizado para uma melhor compreensão do sistema de fiação e drenagem, esses sistemas foram criados com o intuito de melhorar a estética nas ruas, retirando a fiação e os postes que tanto as poluem visualmente.

Imagem 5 - Corte esquemático.

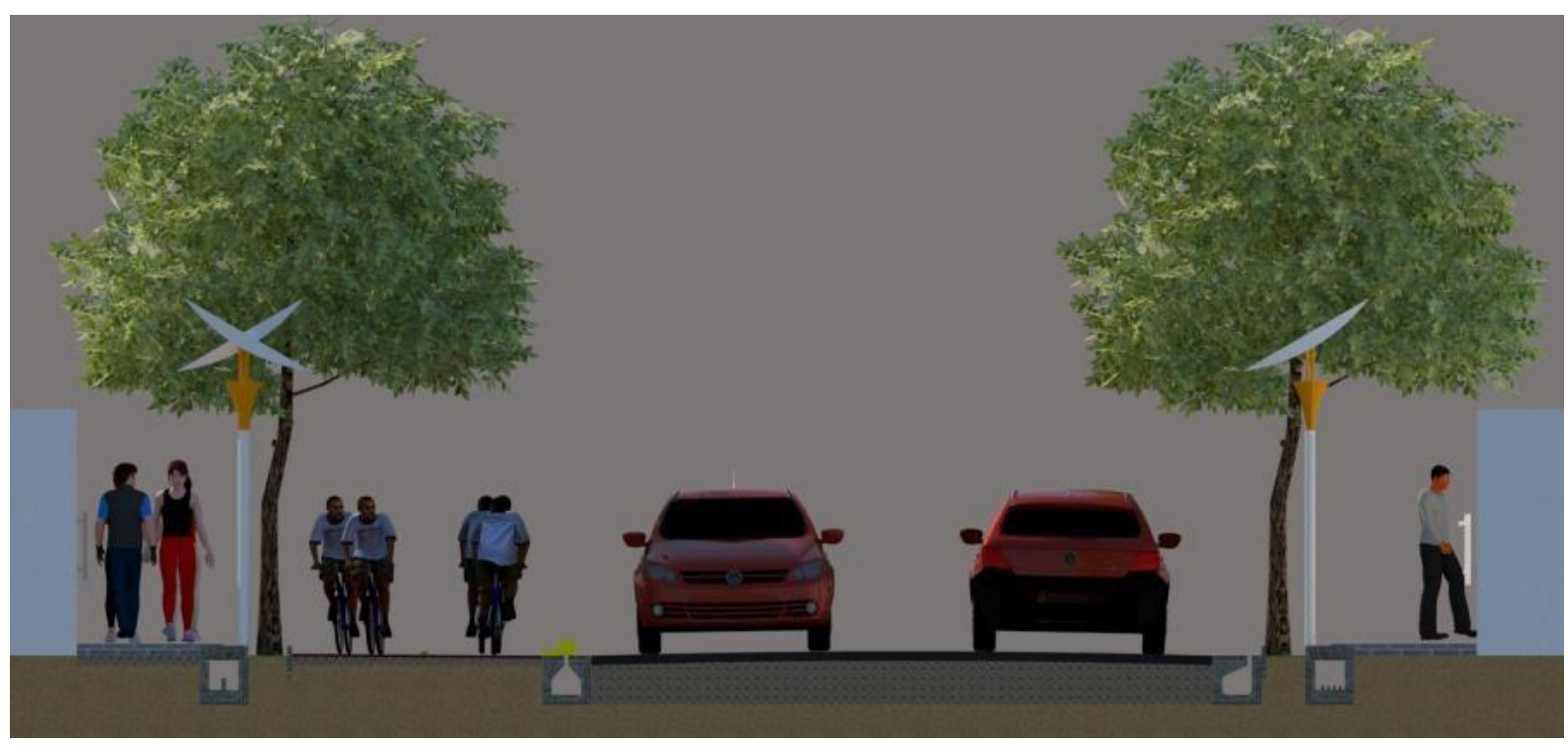

Fonte: Acervo pessoal.

$\mathrm{Na}$ imagem 06, observa-se uma melhor distribuição dos espaços e equipamentos urbanos, com postes de iluminação duplos do lado da ciclovia localizados entre a vegetação, que se encontram dispostos a cada 10 metros com intercalada de 5 metros na fileira do lado oposto à ciclovia, o que melhora a iluminação artificial devido a triangularidade. 
Imagem 6 - Vista superior.

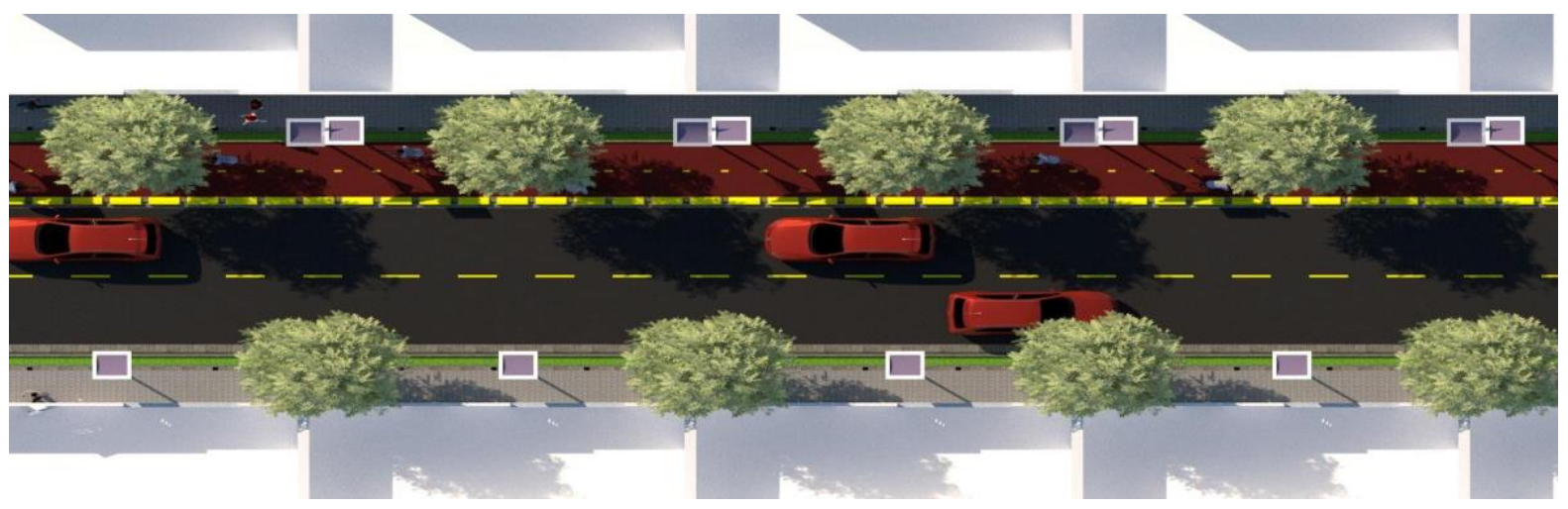

Fonte: Elaborado pelo autor.

Os itens que compõem o sistema de drenagem pluvial possuem um funcionamento simples, com dimensões externas de 50 centímetros de largura e altura e 1 metro de comprimento com uma abertura superior de 4 centímetros para a entrada da água e o interior vazados no meio, com dois formatos, como pode ser visto nas imagens 7 e 8 , na primeira com um desenho projetado para ser utilizado no canto do meio fio, enquanto na última imagem tem um formato pensado para ser utilizado entre a ciclovia e a faixa de rolagem de veículos automotor. A última terá ainda a função de suportar o meio fio que segrega a ciclovia. Na prancha $05 / 07$, disponível no apêndice, encontra-se o detalhamento.

Imagem 7 - Duto de drenagem pluvial (01) Imagem 8-Duto de drenagem pluvial (02)

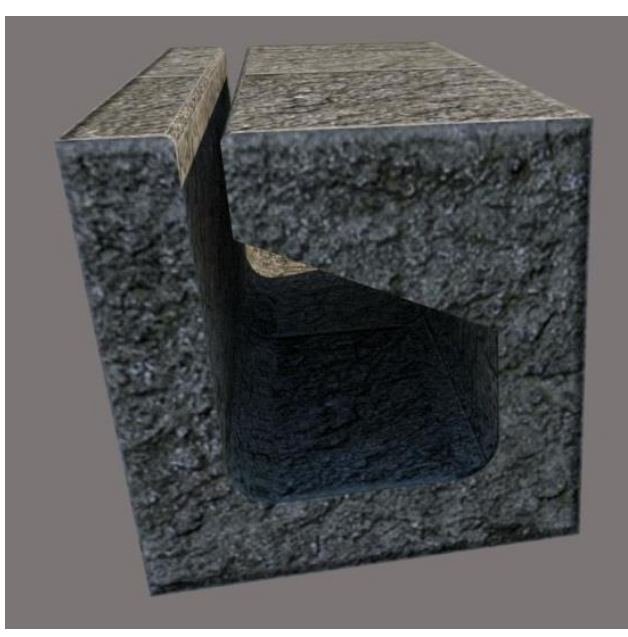

Fonte: Elaborado pelo autor.

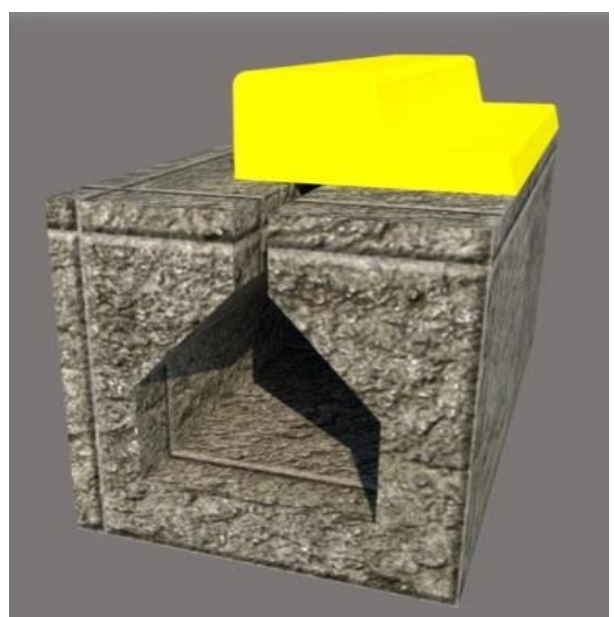

Fonte: Elaborado pelo autor. 
Os sistemas de drenagem pluvial, o sistema de fiação, rede elétrica e internet também foram propostos pelo autor, elaborados em peças de concreto medindo 50 centímetros de largura, 60 de altura e 80 de comprimento, apresentando como única diferença a distribuição na parte interna. $\mathrm{Na}$ imagem 9 , observa-se uma separação no duto para dividir a fiação positiva da negativa, e a imagem 10 representa as 5 divisões mais baixas para distribuir a fiação da internet. Devido à manutenção do sistema de internet ser mais frequente que o da rede de distribuição de energia, ele deverá sempre estar alocado na faixa de serviço oposta à da ciclovia para evitar transtornos entre os operários das operadoras de internet e os ciclistas.

Imagem 9 - Duto de rede elétrica.

internet.

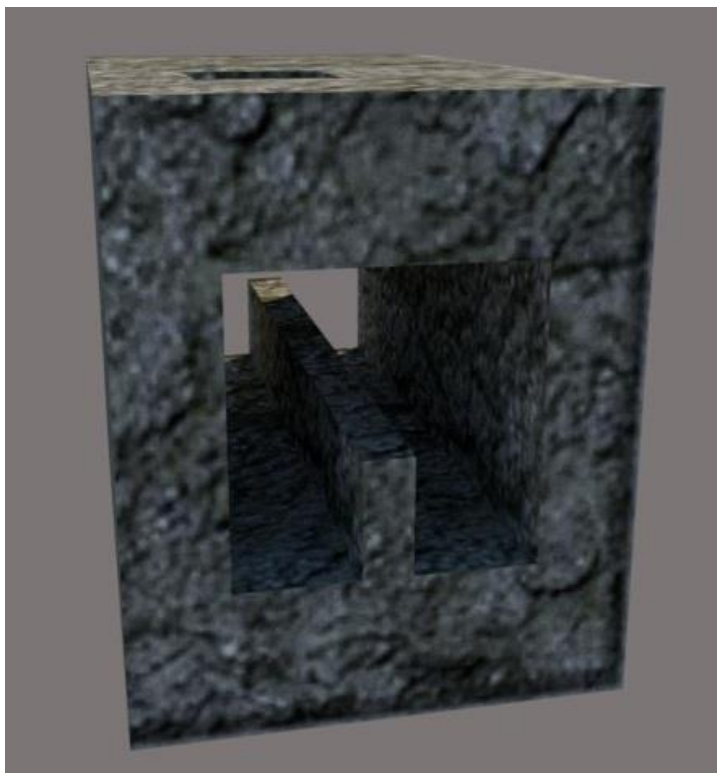

Fonte: Elaborado pelo autor.
Imagem 10 - Duto de fiação de

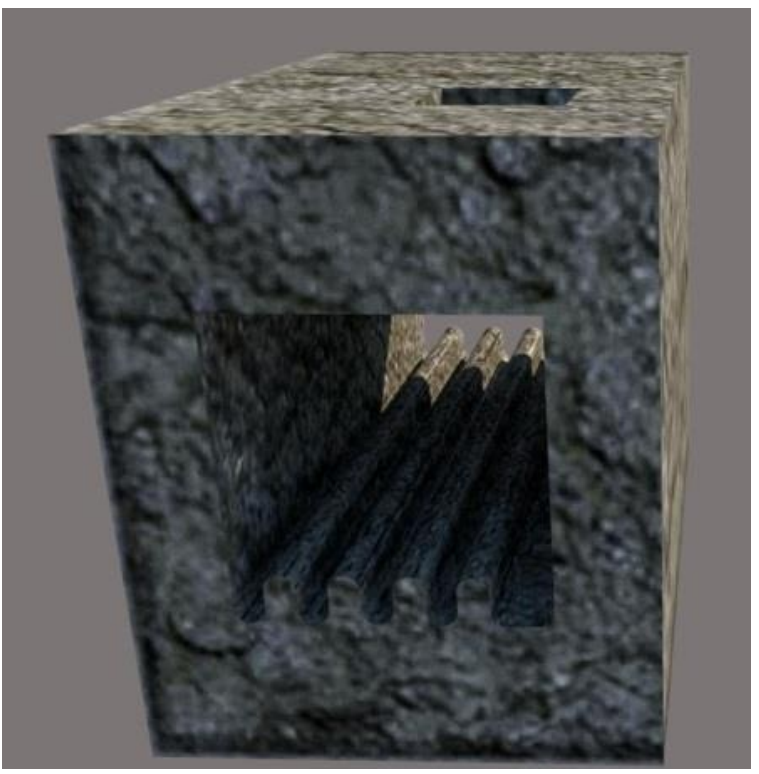

Fonte: Elaborado pelo autor.

A ciclovia às margens da BR 230 ficará totalmente isolada de outras construções, implantada na faixa de domínio do Departamento Nacional de Trânsito (DNIT), com um mínimo de 10 metros do acostamento e de 6 metros dos lotes que se situem em seu percurso. Dessa forma, fica uma área de escape para a BR e espaço suficiente para os donos dos lotes não precisarem parar em cima da ciclovia. 
A mesma apresenta uma iluminação independente, solar e indireta e vegetação distribuída com as mesmas dimensões que na parte implantada na malha urbana.

Nas imagens 11 e 12, observa-se a planta esquemática e uma imagem renderizada da ciclovia facilitando a compreensão de como a mesma irá instalar-se ao longo da BR, ficando a BR paralela à parte superior da imagem e os lotes paralelos a parte inferior. Detalhes técnicos de dimensões estão na prancha 03-07 nos apêndices.

Imagem 11 - Planta esquemático ciclovia as margens da BR 230.

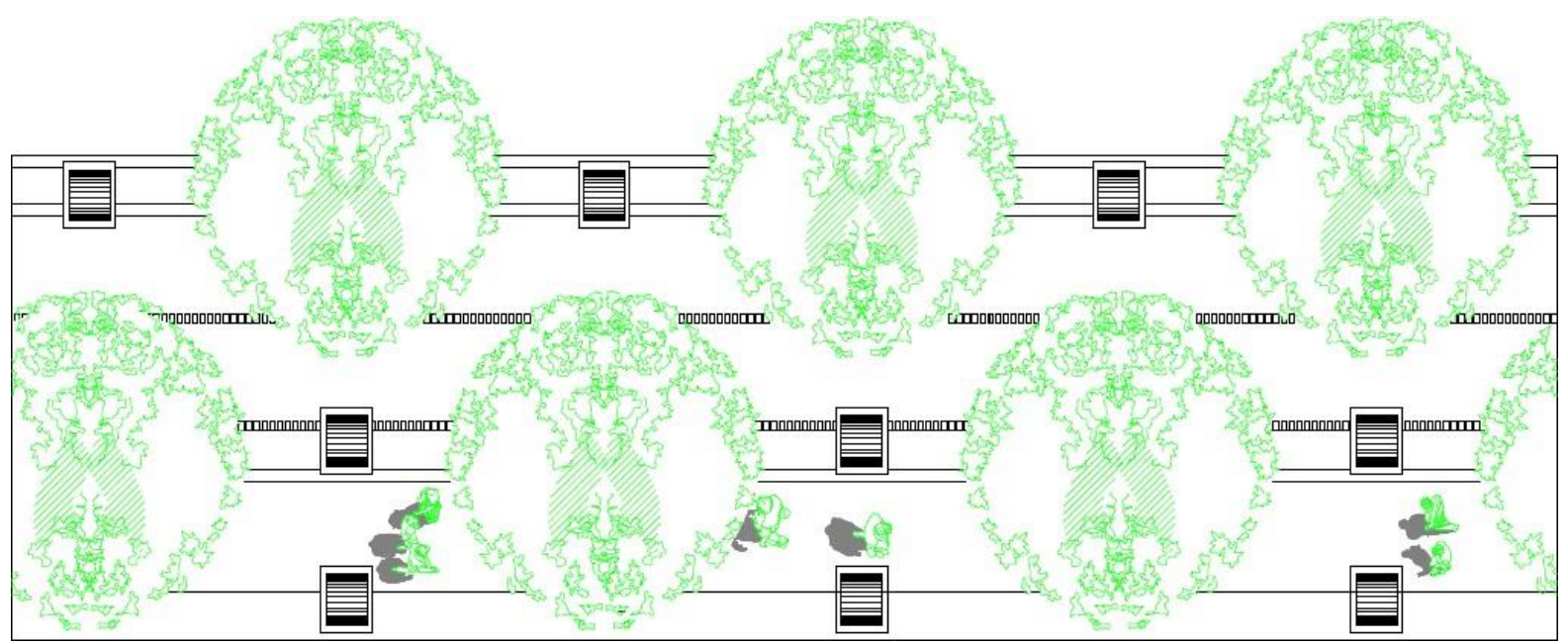

Fonte: Elaborado pelo autor.

$\mathrm{Na}$ imagem 12, pode-se observar que a representação da BR com veículos inseridos demonstra que o trafego é feito em mão dupla, o que deixa quem trafega em seu acostamento em maior vulnerabilidade, pois neste tipo de via existe apenas uma faixa de rolagem por sentido e em muitos casos o condutor necessita fazer uso do acostamento. Por este motivo, foi proposto em paralelo com a ciclovia uma faixa de pedestres, proporcionando maior conforto aos que transitam a pé e podendo ainda ser utilizada para fins esportivos e de lazer, como pista de cooper. 
Imagem 12 - Vista superior da ciclovia as margens da BR 230 (renderizada).

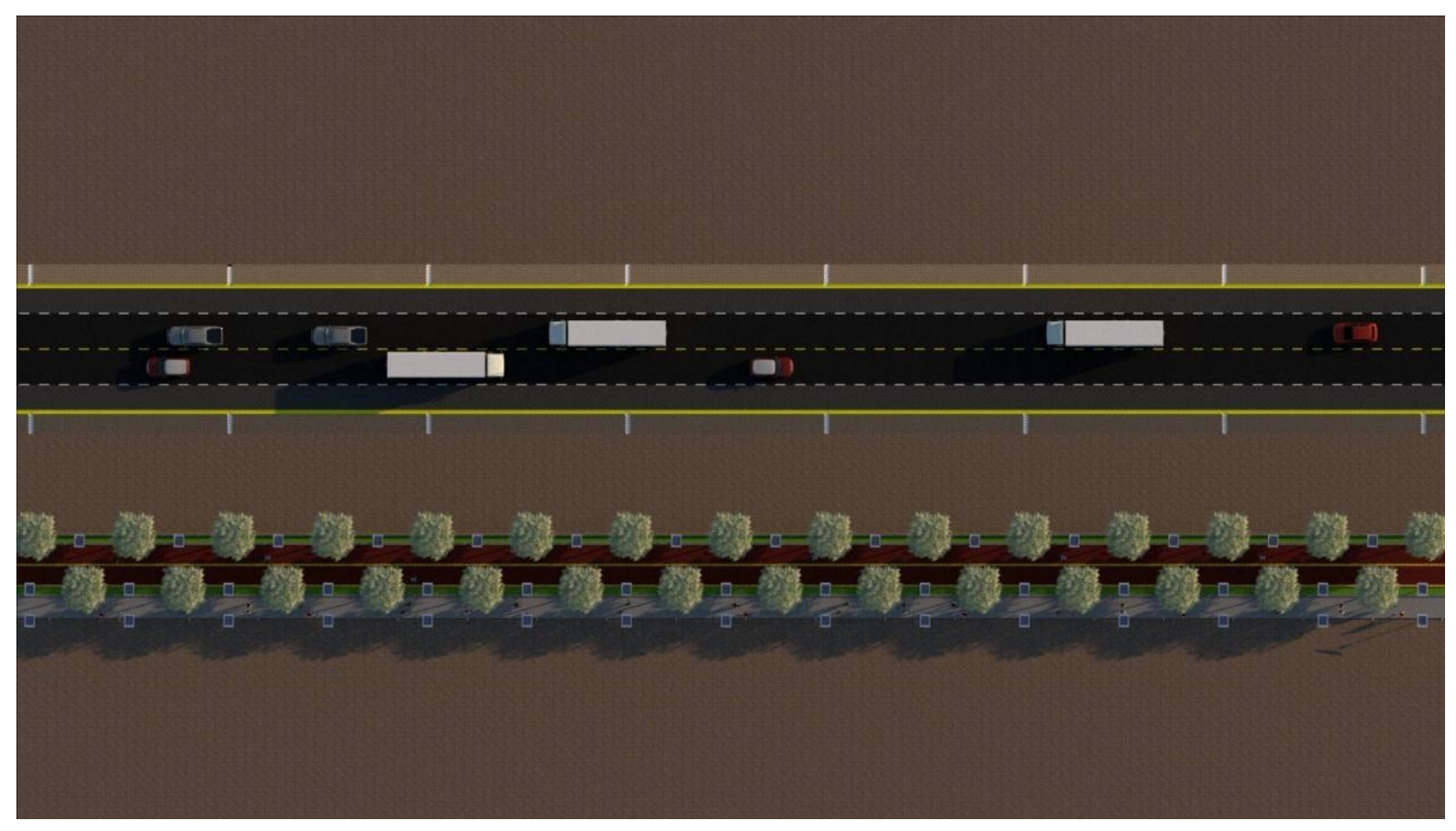

Fonte: Elaborado pelo autor.

Com uma perspectiva da ciclovia proposta para a margem da BR 230, percebe-se melhor o funcionamento da mesma e os itens propostos para evitar transtornos. A imagem 13 mostra que a pista central e o acostamento são mais elevados que a área de escape e a ciclovia, o que ocorre com muita frequência ao longo da via, e com o intuito de evitar erosões e facilitar a travessia de pedestres foi proposto uma canaleta ao longo desses trechos, destacada em amarelo e representada na imagem $14 \mathrm{com}$ as escadas que servem tanto para facilitar a travessia de pedestres quanto para escoar a água sem danificar o talude. 
Imagem 13 - Perspectiva da ciclovia as margens da BR 230 (renderizada).

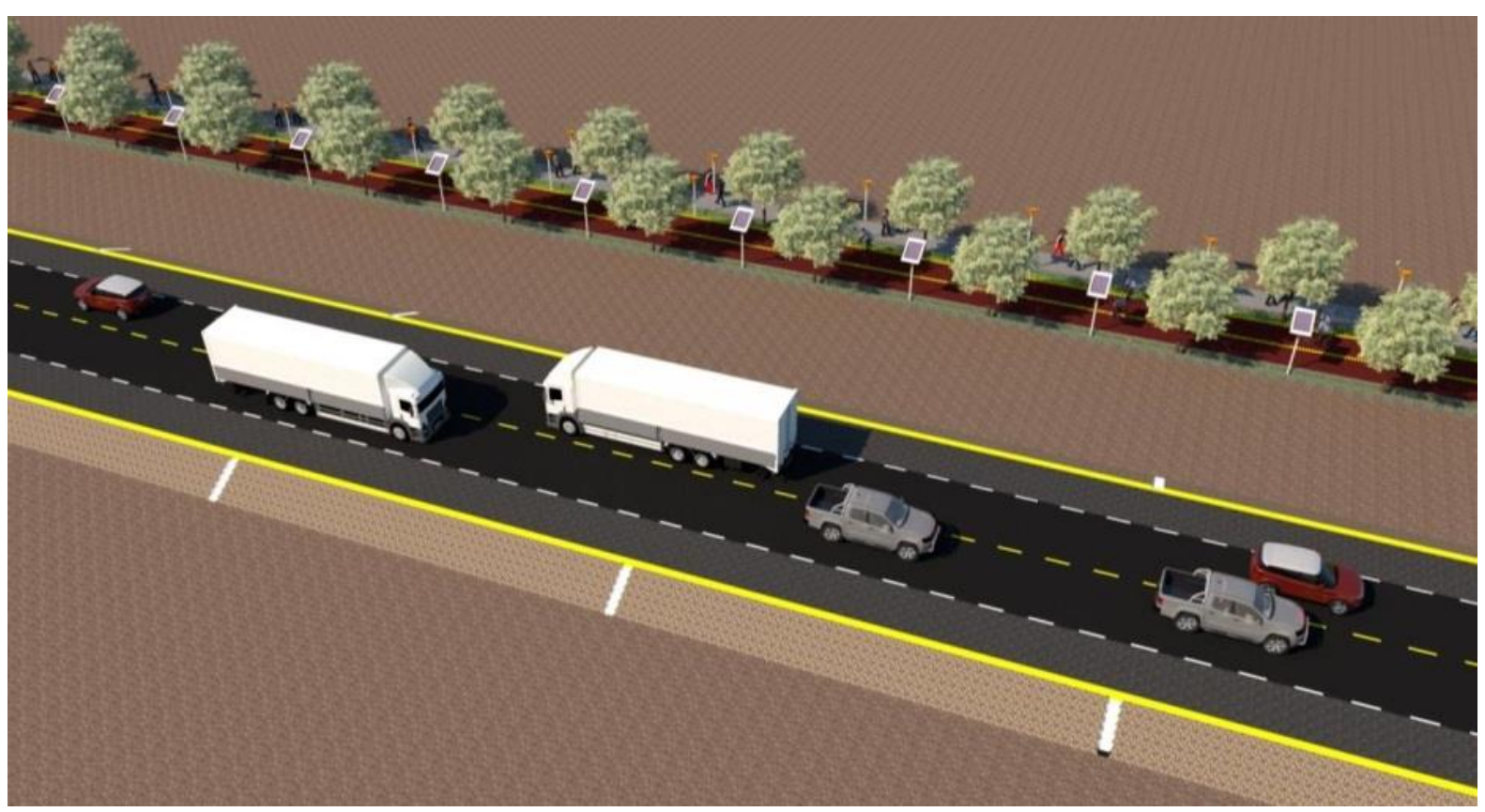

Fonte: Elaborado pelo autor.

Imagem 14 - Vista do talude com a escada e a canaleta.

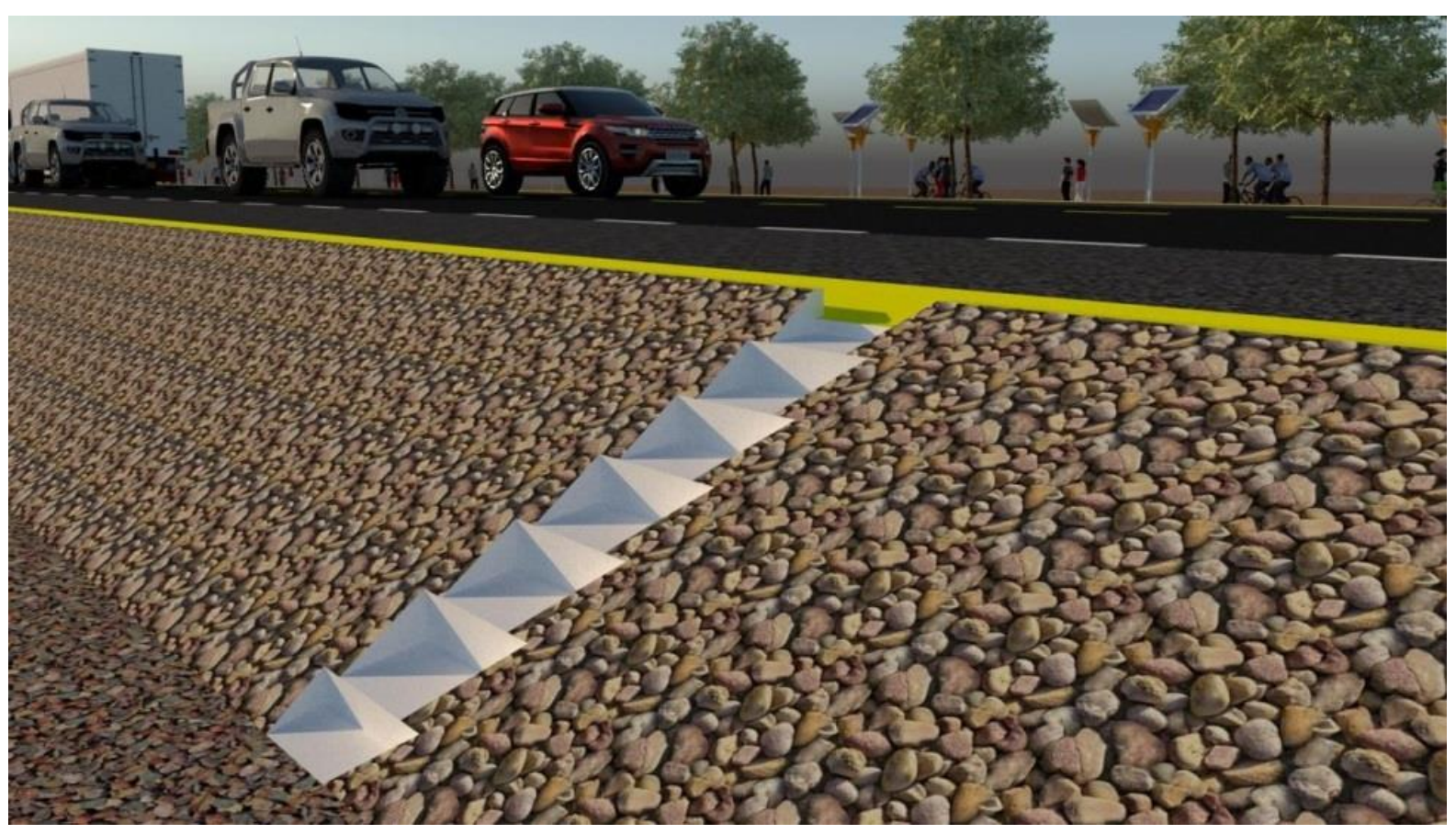

Fonte: Elaborado pelo autor. 
Aprofundando-se para a o funcionamento da ciclovia, percebe-se na imagem 15 que a vegetação e a distribuição é idêntica a implantada na ciclovia da malha urbana, relembrando que a sua distribuição é feita com um afastamento de 10 metros entre eixos e triangulada, o que significa que quando se tem uma planta de um lado, em paralelo tem-se um poste. O que facilita a captação dos raios solares pelas placas que alimentam os postes.

Outra proposta que deve-se ser levada em consideração é que as pistas da ciclovia e da faixa de pedestre ficam mais elevadas que o nível natural do terreno em que será implantada, com isso reduz-se o acúmulo de terra na via, uma vez que a região passa um longo período do ano sem chuvas e o solo durante esse período perde a vegetação rasteira, tornando propício o deslocamento de terra com os ventos. $\mathrm{E}$, durante o período chuvoso, o desnível deve impedir que as pistas fiquem alagadas e/ou enlameadas. A passagem de água ocorre pela tubulação que liga os canteiros ao solo natural com dimensões disponíveis na prancha 03-07 em apêndice e ilustrando o seu funcionamento na imagem 15.

A imagem 15 ilustra também a distribuição dos tachões, que devem estar afastados $5 \mathrm{~cm}$ uns dos outros, por tratar-se de uma ciclovia com longos trechos sem interseções com ruas, podendo assim obter-se velocidades elevadas e quanto maior a velocidade, maiores os riscos em um acidente, e com a implantação dessa forma o ciclista que por ventura vier a se distrair não sofrerá um calço hidráulico forte ao colidir com os tachões. 
Imagem 15 - Visão de quem percorre pela faixa de pedestre.

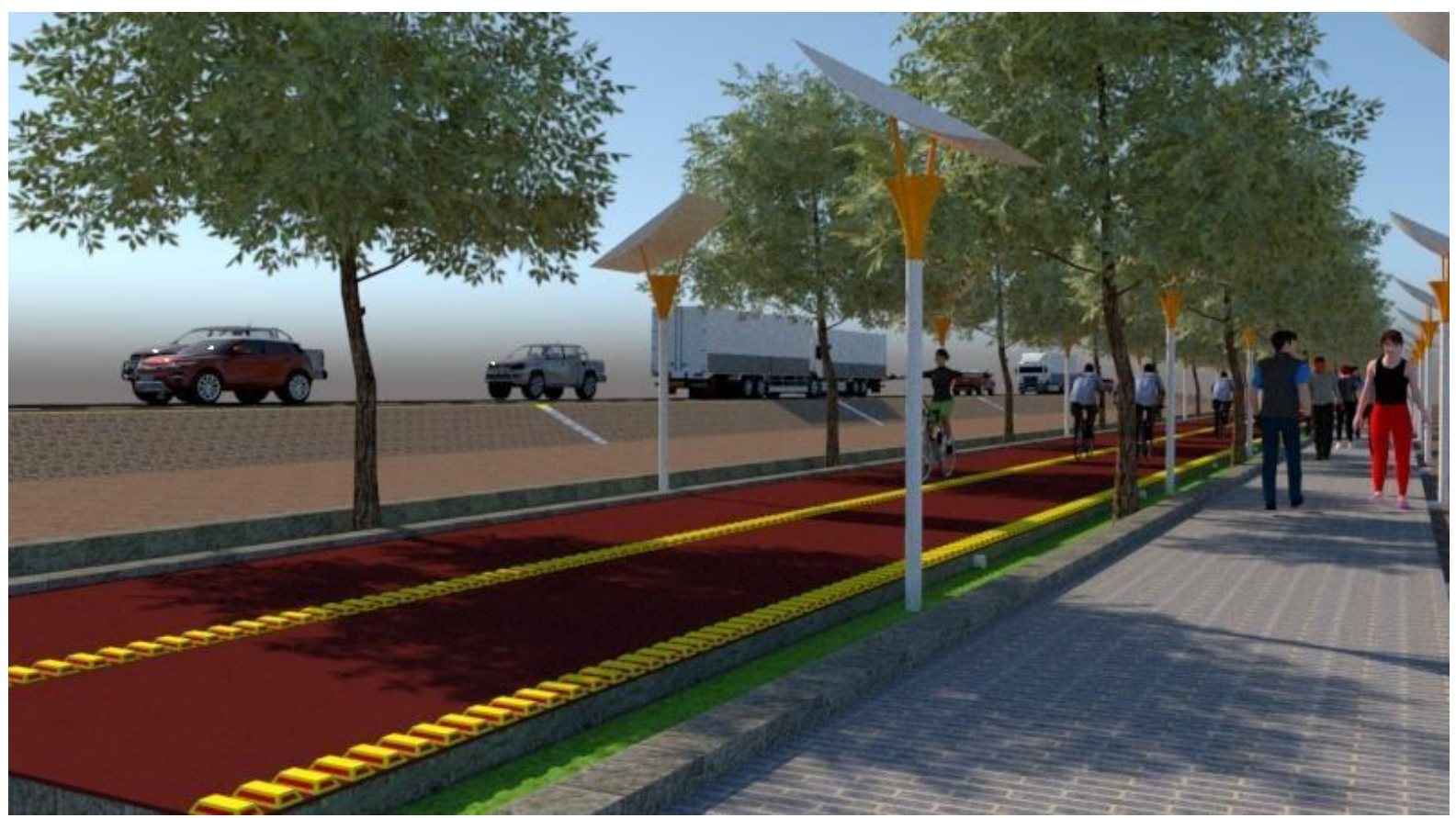

Fonte: Elaborado pelo autor.

\section{CONCLUSÃO}

Com esse projeto, observou-se que o município de Cajazeiras-PB possui um grande potencial para implantação da ciclovia, quando considerados os critérios propostos na metodologia, haja vista que a distribuição de uso e ocupação do solo favorece a sua implantação.

O percurso proposto abrangeu áreas residenciais, industriais, educacionais e áreas de comércio e serviço. Dessa forma, esse projeto contempla um grande número de usuários potenciais ao uso da bicicleta como meio de transporte e/ou para atividades esportivas e recreativas.

Devendo ainda ressaltar que, com a implantação de uma ciclovia, o município pode criar medidas educativas de incentivo da bicicleta como meio de transporte. 
Espera-se que esse trabalho sirva de base para elaboração de novos projetos que aprimorem a malha cicloviária proposta para o município incluindo ciclofaixas, ciclorotas e equipamentos de apoio aos ciclistas.

\section{REFERÊNCIAS BIBLIOGRÁFICAS}

ASSOCIAÇÃO BRASILEIRA DE NORMAS TÉCNICAS (ABNT). ABNT NBR 9050. Acessibilidade a edificações, mobiliário, espaços e equipamentos urbanos. $3^{\text {a }}$ edição. ABNT, 2015. Disponível em: https://www.ufpb.br/cia/contents/manuais/abnt-nbr9050-edicao2015.pdf. Acesso em: 01 de maio de 2019.

BRASIL. LEI 13.724 de 04 de outubro de 2018. Institui o Programa Bicicleta Brasil (PBB) para incentivar o uso da bicicleta visando à melhoria das condições de mobilidade urbana. Diário Oficial da União, 05 de outubro de 2018, p. 3, 2018. Disponível em: http://www.planalto.gov.br/ccivil_03/_ato2015-2018/2018/Lei/L13724.htm. Acesso em: 01 de março de 2019.

BRASIL. Lei no 12.587 , de 3 de janeiro de 2012. Institui as diretrizes da Política Nacional de Mobilidade Urbana; revoga dispositivos dos Decretos-Leis $\mathrm{n}^{\text {OS }} 3.326$, de 3 de junho de 1941, e 5.405, de 13 de abril de 1943, da Consolidação das Leis do Trabalho (CLT), aprovada pelo Decreto-Lei $n^{0} 5.452$, de $1^{\circ}$ de maio de 1943 , e das Leis $n^{\text {OS }} 5.917$, de 10 de setembro de 1973, e 6.261, de 14 de novembro de 1975; e dá outras providências. Diário Oficial da União, 04 de janeiro de 2012, p. 1. Brasil, 2012. Disponível em: http://www.planalto.gov.br/ccivil_03/_ato2011-2014/2012/lei/l12587.htm. Acesso em: 10 de março de 2019.

BRASIL. Lei ํㅜ 9.503, de 23 de setembro de 1997. Institui o Código de Trânsito Brasileiro. Diário Oficial da União, Seção 1, 24 de setembro de 1997, p. 21201, 1997. Disponível em: http://www.planalto.gov.br/ccivil_03/leis/19503.htm. Acesso em: 15 de dezembro de 2018.

BRASIL. MINISTÉRIO DAS CIDADES. Mobilidade e política urbana: subsídios para uma gestão integrada. Rio de Janeiro: IBAM; Ministério das Cidades, 2005. 52 p.

Disponível em: http://www.ibam.org.br/media/arquivos/estudos/mobilidade.pdf. Acesso em: 05 de abril de 2018.

BRASIL. MINISTÉRIO DAS CIDADES. Secretaria Nacional de Transporte e da Mobilidade Urbana. Caderno de Referência para Elaboração de Plano de Mobilidade por Bicicleta nas Cidades. Brasília: Secretaria Nacional de Transporte e da Mobilidade Urbana, 2007. p. 232. Disponível em: http://www.ta.org.br/site/Banco/7manuais/cadernosite2007xz.pdf. Acesso em: 05 de abril de 2018.

DICIONÁRIO ONLINE DE PORTUGUÊS (DICIO). Mobilidade. 2018. Disponível em: https://www.dicio.com.br/mobilidade/. Acesso em: 01 de abril de 2018.

FURTADO, A. C. Direito ao transporte na constituição federal brasileira de 1988: A bicicleta como meio de transporte alternativo para a mobilidade urbana. Revista de Direito Fibralex,

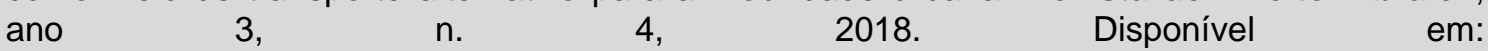
http://periodicos.fibrapara.edu.br/index.php/fibralex/article/view/63. Acesso em: 05 de abril de 2018.

GEIPOT. Manual de Planejamento Cicloviário. 3 ed. ver. e amp. Brasília, DF, 2001. 
Disponível

http://projects.mcrit.com/tiete/attachments/article/291/Manual\%20de\%20planejamento\%20ciclov i\%C3\%A1rio\%20-\%20GEIPOT\%20-\%202001.pdf. Acesso em: 10 de julho de 2018.

INSTITUTO BRASILEIRO DE GEOGRAFIA E ESTATÍSTICA (IBGE). Panorama das cidades. IBGE, 2018. Disponível em: https://cidades.ibge.gov.br/brasil/pb/cajazeiras/panorama. Acesso em: 10 de fevereiro de 2019.

INSTITUTO DE PESQUISA ECONÔMICA APLICADA (IPEA). A mobilidade urbana no Brasil. IN: IPEA. Infraestrutura social e urbana no Brasil: subsídios para uma agenda de pesquisa e formulação de políticas públicas/ Instituto de Pesquisa Econômica Aplicada. Brasília: Ipea,

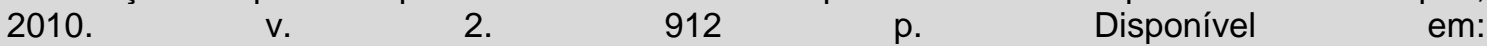
http://ipea.gov.br/agencia/images/stories/PDFs/livros/livros/42543_Livro_InfraestruturaSocial_vo 12.pdf. Acesso em: 05 de abril de 2018

LIBARDI, R. MOBILIDADE URBANA FRENTE À COMPLEXIDADE URBANA. EURE (Santiago), Santiago, v. 40, n. 121, p. 273-276, set. 2014 . Disponível em: https://scielo.conicyt.cl/pdf/eure/v40n121/art13.pdf. Acesso em: 05 de abril de 2018.

OLIVEIRA, J. M. Identificação de fatores que contribuem para o uso da bicicleta como transporte urbano. Dissertação (Programa de Pós-Graduação em Arquitetura e Urbanismo). Universidade Federal de Santa Catarina, Florianópolis, 2012. 173 p. Disponível em: https://repositorio.ufsc.br/handle/123456789/100380. Acesso em: 06 de abril de 2018.

REIS, M. A. S. Modalidade urbana: um desafio para gestores públicos. Cadernos FGV Projetos, 2014. Disponível em: http://bibliotecadigital.fgv.br/dspace/handle/10438/16446. Acesso em: 08 de julho de 2018.

RUBIN, B.; LEITÃO, S. O Plano de Mobilidade Urbana e o futuro das cidades. Estudos avançados, $\quad$ v. 27, n. 79, 2013. Disponível em: http://www.scielo.br/scielo.php?script=sci_arttext\&pid=S0103-40142013000300005. Acesso em: 10 de junho de 2018.

SAVOLDI, P. A.; PRIESS, A. S. Mobilidade urbana e o uso da bicicleta como método alternativo de locomoção. IX congresso brasileiro de direito urbanístico. Florianópolis- Santa Catarina, 2017. Disponível em: https://jus.com.br/artigos/64941/mobilidade-urbana-e- o-uso-da-bicicletacomo-metodo-alternativo-de-locomocao. Acesso em: 12 de junho de 2018.

SILVA, A. Mobilidade urbana e equidade social: possibilidades a partir das recentes políticas de transporte público na Metrópole do Rio de Janeiro. Revista de Geografia e Ordenamento do Território (GOT), n. ${ }^{-}$10, p. 293-317, 2016. Disponível em: http://www.scielo.mec.pt/scielo.php?script=sci_abstract\&pid=S2182-12672016000200015.

Acesso em: 14 de junho de 2018.

SILVA, M. S. S. O uso de bicicletas como modal para a mobilidade urbana no município de castanhal, estado do Pará. 2017. Monografia (Especialização em Gestão do Trânsito) Universidade do Sul de Santa Catarina, Santa Catarina. Disponível em: https://riuni.unisul.br/handle/12345/2386. Acesso em: 15 de junho de 2018.

SIMONI, J. H. et al. Conflito entre pedestre e ciclovia: um estudo de caso da avenida Mandacaru em Maringá - pr. Revista Eletrônica em Gestão, Educação e Tecnologia Ambiental Santa Maria Revista do Centro de Ciências Naturais e Exatas - UFSM, v. 19, n. 2, $\quad$ p. $\quad$ p. $\quad 587-594, \quad 2015 . \quad$ Disponível em: https://periodicos.ufsm.br/reget/article/viewFile/16963/pdf. Acesso em: 18 de junho de 2018.

SOUZA, P. B. Análise dos fatores que influem no uso da bicileta para fins de planejamento cicloviário. Tese de Doutorado. Universidade de São Paulo: São Carlos, 2012. 190 p. Disponível em: http://www.teses.usp.br/teses/disponiveis/18/18144/tde-11122012- 
092959/pt-br.php. Acesso em: 18 de junho de 2018.

VALE, D. S. A cidade e a bicicleta: uma leitura analítica. Finisterra, v. 51, n. 103, p.45-66, 2016. Disponível em: https://revistas.rcaap.pt/finisterra/article/view/7077. Acesso em: 19 de junho de 2018.

VASCONCELLOS, E. A. O transporte urbano no Brasil. Le Monde Diplomatique, n. 59, 2012. Disponível em: https://diplomatique.org.br/o-transporte-urbano-no-brasil/. Acesso em: 20 de junho de 2018. 